\title{
Developing an Integrated Framework for Sustainable Development of Poyang Lake Watershed*
}

\author{
DAI XingZhao ${ }^{1} \&$ Haikai Tane ${ }^{2}$ \\ (1:Mountain River Lake Region Development Commission, Jiangxi Province, P.R.China;
}

2: Watershed Systems Center for Catchment Ecology, New Zealand)

\begin{abstract}
The framework for sustainable development of watersheds described in this paper is an ecosystem model capable of economic evaluation based on watershed systems theory and practice, by taking Poyang lake watershed as a case. This integrating framework proposed has three primary components (a) environmental policy and planning, (b) geospatial information systems, and (c) community development and regional networks. The framework unites disciplines like watershed ecology, environmental planning, sustainable development and resource management in the mapping and modeling and monitoring of the watershed to retain holistic approaches to integrated watershed management.
\end{abstract}

Keywords: Watershed Management, GIS, Poyang Lake Watershed

\section{Introduction}

The Poyang Lake watershed is known as the Mountain-River-Lake (MRL for short) Region of Jiangxi Province, PR China. The region is aptly named for it contains a myriad of mountains, five major rivers, and a larger number of tributary rivers and a suite of man-made and natural lakes. The description is also a useful metaphor emphasizing the geographical connectivity of all parts of watersheds.

The Mountain-River-Lake Regional Development Program originated from a comprehensive study to Poyang Lake in early 1980's and the vision of then Governor of Jiangxi Province in 1985 that there was no one technical answer to the problems faced by Poyang Lake watershed, then or in the future. As stated in the Overall Plan for the Sustainable Development of MRL Region, the guiding principle of MRL Program is that " To manage the lake, the river must be managed, to manage the river the mountain must be managed, to manage the mountain the poverty must be eliminated."

\footnotetext{
* This paper is sponsored by the Sino-EU project-SUCCESS-ICA-CT-2002-10007.

2003-08-16 received; 2004-08-20 accepted. Dai Xingzhao, Male, 1963.12, Adjunction Professor, E-mail:xingzhaod@ vip.sina.com
} 
The critical thing to remember about watersheds is that the rivers, the hill slopes, the mountain tops, and the flood-formed bottom lands are really all part of one watershed system. All are integrated with each other. Streams, rivers, wetlands and floodplains, human habitats and catchment ecosystems from the smallest village to the largest metropolis are inseparable. They are all part of the one functional system - their watershed catchment.

The incremental impact of many seemingly proper actions can be disastrous. Therefore, the "integrated" watershed approach has to be adopted helping avoid this tyranny of small decisions by: (1)Recognising that the provision of clean water and healthy environments for human settlement is a founding tenet of ratified international law forged under UN Agenda 21. (2)Focusing attention on coordinating environmental planning for sustainable development of watershed catchments through capacity building and participatory programs. (3)Developing up-to-date and accurate environmental imagery that is user-friendly and easy to access by communities for protecting environmental systems that govern the performance of watersheds ${ }^{[1]}$ (Tane and Dai 1993). (4)Engaging the community in ceremonies, programs and festivities to rebuild recognition and respect for living water through the arts, culture and social systems in order to rebuild the collective intelligence called common sense.

Developing a framework for sustainable development and environmental protection of the mountains, rivers and lakes of Poyang watershed requires integrating different watershed models and environmental technologies including: (1) Remote sensing data, geospatial imageries and decision support systems. (2) Mapping watershed habitats, regoliths. (3) Establishing benchmark transects for monitoring performance. (4) Modelling land use ecosystems and their resource economies. (5) Monitoring waterways and their environmental performance. (6) Coordinating land use planning and community development. (7) Managing natural resources for the benefit of the whole watershed.

The main methods for achieving effective integration are: (1) Integrated team work by multi-disciplinary teams working collaboratively on key objectives and tasks, with peer review feedback on performance. (2) Integrated resource assessments of watershed habitats, regoliths and water resources to meet study objectives and resolve key issues. (3) Integrated design and development of permanent benchmarks based on strategic planning, remote sensing, geospatial modelling and field surveys. (4) Integrated geospatial information system (iGiS) for mapping, modelling and monitoring the watershed of Poyang Lake.

\section{Environmental Policy and Planning}

Strategic environmental planning for sustainable development of watersheds is necessarily precisely because we cannot forecast, predict or manage the future reliably. Planning is necessary to design and develop the necessary framework and methodologies for sustainable patterns of settlement (Figure 1). Only then with this framework and process in place, is sustainable resource management practicable and effective.

The underlying planning principles used for developing this framework are those in UN 
Agenda 21. With the number of signatories to this international convention reaching the required levels stipulated in 1992 by heads of government from around the world, UN Agenda 21 has now become international law for sustainable development and environmental protection. There is an official summary of the 27 principles contained in Agenda 21.

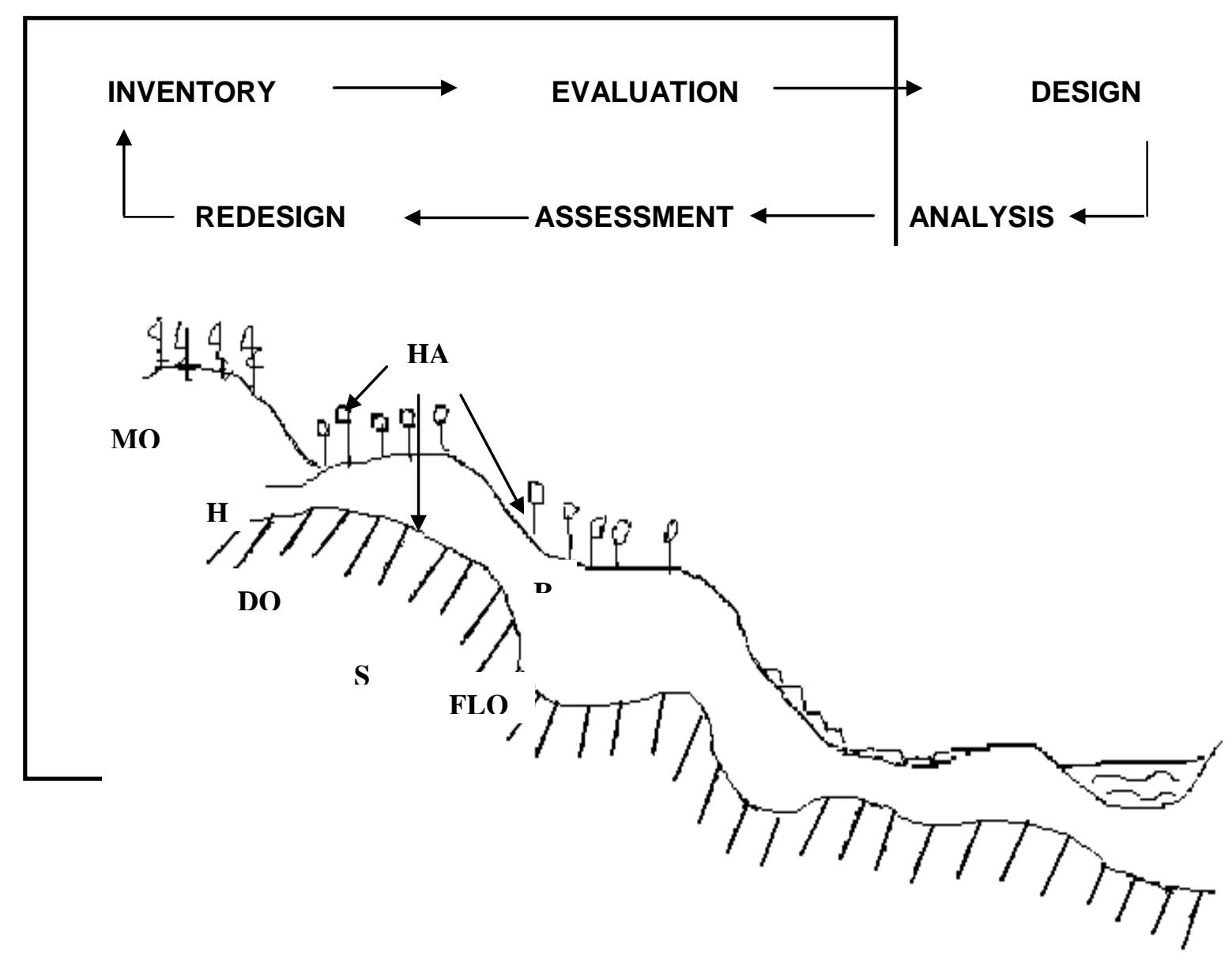

Fig. 1 Environmental Planning for Sustainable Development

UN Agenda 21 is the empowering document of many different initiatives, local, regional and international. Both the United Nations Environment Program and Food and Agriculture Organisation of the United Nations in recent years have highlighted the implications of Agenda 21 for land and water resource management ${ }^{[2-4]}$. China has published its national Agenda 21 in 1994. MRL program is in priority one of China agenda 21 policy statement on population, environment and development.

UN Agenda 21 transcends the resource management paradigm in many ways. Management models are about making the best use of what we have, of managing resources and the environment wisely. This is the resource conservation model that dominated conservation 
thinking in the 20th century ${ }^{[5]}$.

It is important to recognise that the UNEP/FAO focus on natural resource management, land and water management and sustainable management of the environment is only part of the holistic picture contained within Agenda 21. UNESCO's programs FOR EXAMPLE, are more focussed on integrating cultural and scientific aspects of Agenda 21 through various programs such as World Heritage Areas.

Many hill and mountain lands in the Poyang watershed are still very degraded. They are unable to perform normal watershed functions like storm water retention in regolith aquifers. In degraded environmental areas there is an urgent need to focus more on strategic planning for ecologically sustainable development rather than rely on sustainable resource management. It is important to benefit from the environmental restoration of landscapes through integrating conservation and development. This requires environmental planning for sustainable development.

Agenda 21 transcends the resource management model and promotes a new set of more democratic and holistic models as the dominant paradigm for environmental protection and human settlement. Called environmental conservation by Dasman it is now generally referred to as ecologically sustainable development ${ }^{[5]}$. Unlike sustainable management by technical experts controlling natural resources, ecologically sustainable development is focussed on social equity and ecological dynamics of cultural change. The objective is making the world a safer, more healthy place to live though sustainable development of the environment.

The review of MRL watershed programs, information and mapping systems indicates there may be some confusion between the two approaches in MRL programs, policies and terminology. It is not surprising that there will be a tendency for people in resource organisations (most of whom are very competent in management or technical methodologies) to adopt new policy terminology without changing their normal models, strategies, methods or tools. This is a serious institutional dilemma preventing essential changes. Failure to accept the need for retraining and retooling by key professions has fatally compromised the New Zealand Resource Management Act and continues to undermine the effectiveness of environmental policy and planning legislation in the Australian states.

Understanding this dilemma is fundamental to resolving it. The dilemma is conspicuous within the Australian and New Zealand planning professions. Government policy in the 1980's and 1990's required fundamental shifts away from state managed regulatory planning to environmental planning for ecologically sustainable development. This required a profound shift from traditional town and country planning to environmental planning for sustainable development. In both countries, however, entrenched academic and professional planning interests failed to recognise and did not accept the need for retraining. Instead they adopted the new terminology like "integrated, holistic and environmental" and continued to use old and outdated management planning methods they studied at university many years ago. As a result new and innovative environmental planning legislation failed to produce the results desired by 
policy makers or anticipated by the community. In both countries there is now an urgent need for comprehensive retraining and capacity building in the very professions required to implement government policy for sustainable development.

It is necessary to recognise that the technocratic and regulatory approach of resource management is being replaced with more equitable participatory approaches of community development through environmental planning frameworks. Resource organisations do not necessarily disappear, however their roles and responsibilities change in fundamental ways.

To help clarify this important issue, so that policies for integrated environmental programs can be implemented more effectively, an overview of the environmental planning for sustainable development process is provided in Figure 2.

\section{Intelligent Geospatial Imaging System (iGIS)}

One of the major components of the framework is the Poyang lake watershed iGIS, which is as a common geospatial framework for networking all stakeholders and agencies.

Intelligent geospatial imaging systems (iGiS) are strategically structured decision support systems based on specially prepared true and false environmental imagery. The true imagery provides the geospatial platform; the false imagery provides specific information about the environment that is not visible to the human eye.

True imagery - like panchromatic and true colour photography - is what people normally see. True imagery provides information that can be verified by human eyesight. False imagery is captured by a range of instruments that scan wave lengths outside the human eye range. False imagery provides specialised information like infra red, ultra violet and other geomagnetic data on bandwidths beyond human vision. In computer terminology all environmental imagery is called raster imagery.

Both true and false environmental imagery are cartographically designed so that different sets of information commonly required in watershed projects can be manipulated, compared or merged together. For reliable results it is essential that the environmental imagery is accurate and up-to-date.

Before environmental imagery became readily available, maps were made by combining different lines and symbols to represent real world phenomena. In computer terminology cartographic line work and symbols are called vector information. Vector information can be imported and displayed over the raster imagery as required for particular purposes. As a result of scale inaccuracies and different geographic projections vector information derived from older mapping sources may misfit or conflict with recent and accurate raster imagery.

An overview of the modelling strategy for developing a Poyang Lake Watershed iGiS follows:

\section{Environmental Imagery (Raster)}

1) Acquire or prepare true environmental imagery at a scale and resolution that meets the 
PROFESSIONAL DISCIPLINE

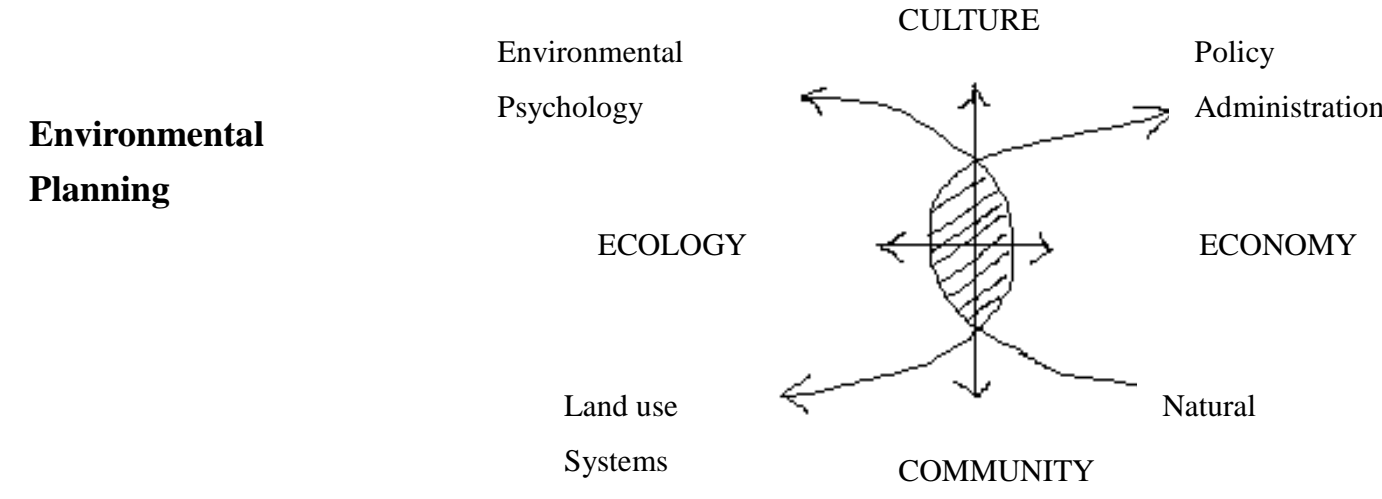

for

National Policy + International Law

UN AGENDA 21

27 PRINCIPLES

for sustainable development

through participatory societies

of

Environmental Protection

Watershed

Watershed

Catchments

Eco-structures

for Ecologically

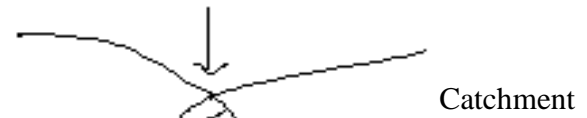

Sustainable

Infrastructures for

Servicing Human

Settlement

Enables

\section{Sustainable Development}

Fig. 2 Integrating Policy and Planning for Sustainable Watershed 
1) needs and requirements of a geospatial platform for the project.

2) If necessary, acquire or prepare false environmental imagery that meets particular requirements of the project, like infra-red or radar imagery.

\section{Biophysical Datasets (Vector)}

3) Capture and confirm geographic data - for example locations, placenames and infrastructure networks significant to the project

4) Capture and confirm key data sets as points and polygons complete with attributes - for example regoliths, habitats and atmospheric energy systems

\section{Object Oriented Database}

5) Establish an object oriented database that will support geospatial modelling needs of the project

6) Develop a modelling strategy and iGiS database structure that enables decision support systems and geospatial simulations

\section{Establishing Permanent Benchmarks}

7) Select permanent representative benchmarks across the watershed and develop suites of benchmark transects for correlating key datasets

8) Capture and confirm vector datasets complete with metadata dictionaries showing how they were captured, their accuracy and reliability

\section{Complete Watershed Mapping}

9) Finish vector datasets of the watershed using remote sensing techniques and interpolation methods from both true and false environmental imagery

10) Complete database with peer reviews for quality assurance purposes, with field testing for determining accuracy and reliability of units and attributes

The integrated framework proposed in this paper is based largely on watershed iGIS model for benchmarking watersheds and ground truthing satellite imagery. The most important element in accurate benchmarking is up-to-date and accurate true imagery. False imagery, like Landsat TM and other multi-spectral imagery, generates false digital data that may be very hard to identify, isolate and distinguish from true data. Furthermore, the use of false imagery like Landsat TM generates much greater field work loads ground-truthing mapping units and resource assessments.

Where accurate, up-to-date, true image mapping is available, such as digital orthophoto mapping draft mapping can usually be confirmed with a single field inspection. Where false imagery is all that is available, as is the case at present in Mountain-River-Lake development Office (MRLDO), reliable assessments will require several field inspections of each benchmark to achieve equivalent levels of reliability.

False imagery is more useful when it can be used in conjunction with true imagery. It is not however, a suitable substitute. For this reason benchmarking the Gan River required additional transects for each benchmark and will require additional field checking. This adds considerably to the time, costs and resources required for reliable benchmarking to set cartographic standards. 
True panchromatic imagery is preferred for many benchmarking purposes. If true colour photography is all that is available it is better to convert it into grey scale for pattern recognition purposes; true colour tends to focus attention on pieces (components) not patterns

When working with maps it helps to remember they are only cartographic models with a range of inbuilt biases. It is not wise to work only with one type of map for the cartographic bias will certainly influence assessments and outcomes. It is good practice to use at least two and preferably three or more different types of mapping. We used three different mapping systems for each benchmark: topographic maps of various vintage, Landsat imagery (1998) and Sino-Brazil imagery (2000). Photographic records were taken of each benchmark. Draft mapping was captured on the Sino-Brazil imagery, compared with the older Landsat imagery and checked with the topography to confirm location. Locations were corroborated using GPS.

\section{Community Development and Regional Networks}

A key step in environmental planning for sustainable development of watershed catchments, perhaps the most important from the view of stakeholders, is reaching agreement on a sustainable development strategy. Both participatory approaches and capacity building methods are necessary to gain the commitment of stakeholders to this important instrument. Without this agreement there is insufficient community commitment to a long-term vision suitable for coordinating sustainable development initiatives within the watershed.

The participatory approach to community planning and rural development has a rich heritage and history in Australia, New Zealand and Canada dating back to the early 1970's. In some countries it is a relatively new method being introduced into wide ranging initiatives from international aid programs to natural resources management.

While affording formal recognition to community participation seems logical it is not without its disadvantages. As an informal process participatory processes tend to be adaptive, flexible and creative. When formalised however, there is a tendency to have formal meetings with agendas rather than working sessions with objectives. This tends to create more friction between different groups and generate sector interest groups with set agendas. As a result the participatory process tends to degenerate into power plays that can become counterproductive. In New Zealand, participatory processes are so formalised by some Regional Councils that they result in orchestrated consultations rather than participatory processes.

Participatory approaches should reflect the preferred way of operating (ie modus operandi) of different stakeholder groups rather than impose the "meeting with agenda" approach on all stakeholders. Australian and New Zealand experience shows that participatory approaches are best left in the hands of stakeholders with their chosen facilitators rather than formalised by government agencies, then taken over and orchestrated by officials. When this happens there is no commitment to and often resistance against the outcomes.

Community capacity building is a multi-faceted approach that covers everything from cultural intelligence and environmental psychology to scientific knowledge and technical skills. Our 
ability to solve environmental problems is not limited by knowledge so much as by outmoded models and theories and cultural metaphors the shape our perceptions. We live at a time of episodic changes including the transition from the industrial to post-industrial society. With the growth of global cultural intelligence the machine-age metaphor for controlling nature is being progressively replaced by a new perspective that blends the older organic metaphor with new technologies for living sustainably within the limits of resilience of natural systems.

The new tools for community capacity building are digital technologies linked to cultural performance. Electronic whiteboards, video cameras and computer gaming systems are used in association with simulation charettes, site workshops, playback theatre and gaming with imagery to develop and record progress in acquiring new skills and perceptions. They are logical extensions of the learning by doing methods used in this project.

Watersheds require common sense approaches far more than rules and regulations. Common sense becomes cultural intelligence, the collective wisdom of society, when it enters the collective unconscious. In the field of environmental psychology, environmental common sense can take hundreds even thousands of years to become so natural and normal that it is no longer recognised or considered as knowledge to be taught. Commons sense cannot be taught or learnt as knowledge because it operates at the subconscious level automatically often from the earliest years. In Jungian psychological terms it has entered into the collective consciousness of the culture. More often than not cultural intelligence is enshrined in cultural myths and legends and reinforced regularly by festivals and other social institutions. They are so apparent that it is taken for granted by most people, much like land tenure and resource assignment systems.

\section{Conclusions}

The framework for sustainable development of watersheds described in this paper is an ecosystems model capable of economic evaluation based on watershed systems theory and practice. The framework is intended to grow and develop in an organized way (with MRLDO coordination) so that the outcome for watershed communities is far better than could be agreed by compromise or plans at the outset. In this respect the framework evokes Chinese cultural intelligence contained in Taoist philosophies, myths and legends for living watersheds. Basically, success begins with cultural respect for living waters.

The integrated framework proposed is trans-disciplinary and eclectic bringing together biophysical sciences with practical applied landscape ecology, resource economics and community development. The uniting process involves enabling science and technology by appropriate cultural and social systems. Networking, cooperation and coordination are enabled through the Poyang Lake watershed iGiS. It provides the playing field (geospatial platform), the game rules (watershed policies, principles) and incentives to play by them (rewards, penalties). The framework will be successful if it engages all stakeholders in a user-friendly and equitable way in accordance with the key principles of UN Agenda 21. 


\title{
References
}

1 Tane H, Dai Xingzhao. Catchment Planning and Conservation Strategies. Australian Journal of Soil and Water Conservation, 1993,6(3)

2 UNEP \& FAO. Our Land Our Future. UNEP \& FAO, Rome, Italy, 1996

3 UNEP \& FAO. Negotiating a Sustainable Future - Structural and Institutional Guidelines. UNEP \& FAO, Rome, Italy, 1997

4 UNEP \& FAO. The Future of our Land - Facing the Future. UNEP \& FAO, Rome, Italy, 1999. UNESCO. Use and Conservation of the Biosphere, UNESCO, Paris. France,1970. UNESCO-UNEP. Connect: UNESCO-UNEP Environmental Education Newsletter, $1992,17(2)$

5 Dasman R. Environmental Conservation. John Wiley \& Sons New York USA, 1959

\section{鄱阳湖流域可持续发展综合模型框架}

\author{
戴星照 ${ }^{1} \quad$ Haikai Tane ${ }^{2}$
}

(1: 江西省山江湖开发治理委员会,南昌 330046; 2: Watershed Systems Center for Catchment Ecology, New Zealand)

\section{提 要}

本文以鄱阳湖流域为例，所描述的流域可持续发展框架是一个基于流域系统理论和实践的生态系统模 型. 包括了三个主要的部分：（1 ) 环境政策与规划；（２）地球空间信息系统； ( 3 ) 社区发展与区域网 络. 框架将多个学科，如：流域生态学，环境规划，可持续发展与资源管理汇集一起，形成了一套综合的 流域制图、模拟和监测的流域管理方法.

关键词：流域管理 GIS 鄱阳湖流域 